\title{
Drug Toxicity of Levonorgestrel (LNGL) targeting biochemical pathways in Drosophila melanogaster
}

\author{
Swaroop G*, Geetha Viswanathan, Reshma Annamati, Geethanjali S, Poornima R \\ MS (Medicinal Chemistry), Newcastle University, United Kingdom \& PhD Scholar (Medical Oncology), International University for \\ Complementary Medicine, Colombo \\ Research Director, Indian Holistic Medical Academy, India \\ PhD scholar (Medical Oncology), International University for Complementary Medicine, Colombo \\ MSc (Biotechnology), M.S Ramaiah Degree College, Bangalore \\ MSc (Organic Chemistry), NMKRV College, Bangalore \\ *Corresponding author E-mail: simhavahini23@gmail.com
}

\begin{abstract}
To achieve maximum contraceptive effectiveness Levonorgestrel tablets (LNGL) are taken exactly as directed and at intervals not exceeding 24 hours. The possibility of ovulation and conception prior to initiation of medication should be considered. Levonorgestrel pill was chosen for our research study since it is widely used by the people to be in command of the unwanted pregnancy and is the number one leading pill in the urban area throughout India. The cornerstone experimental animal in the study of cellular and molecular genetics for over 50 years has been the ubiquitous fruit fly (Drosophila melanogaster). Wheat's cream media with different concentrations from $0.1 \mathrm{mg}$ to 3.0mg of LNGL was prepared to culture Oregon strain of Drosophila melanogaster. Proteins, Carbohydrates and Lipids were isolated and estimated to study the hamperness in the ecdysis of Drosophila melanogaster and also to find out the morphological and toxicological effect. Results were encouraging us to go to the molecular level. Large amount of triglycerides were deposited in the abdomen of drosophila, protein concentration was more in experimental specimen than the control, and number of phenotypic variations were found with the flies treated with medicated LNGL media. "A survey was carried out on the consumption of Levonorgestrel pill in Bangalore urban area, India" in Gynecology department at various hospitals in and around Bangalore, the symptoms seen in the subjects will be presented as evidential proof with respect to our research.
\end{abstract}

Keywords: Abdomen, carcass, Drosophila melanogaster, glycomics, hind gut, Levonorgestrel (LNGL), lipid profile, oral contraceptives, proteomics, progesterone.

\section{Introduction}

Drugs that affect reproduction (both by preventing conception and more recently for treating infertility) have had profound consequences for individuals and for society. The endocrine control of the female and male reproductive systems, because this forms the basis for understanding many important drugs. The principle of negative feedback, which is stressed, is central to understanding how hormones interact to control reproduction, and many drugs, including agents used to prevent or assist conception, work by influencing negative feedback mechanisms. Oestrogen replacement therapy prevents postmenopausal bone loss as well as treating symptoms of oestrogen deficiency, benefits that are offset by effects on the breast and endometrium, and by an increase in thromboembolism. There is a separate section on drugs that alter the contractile state of the uterus, which are important in obstetrics: drugs that stimulate uterine contraction'oxytocic' drugs-are used to induce labour or abortion and to prevent postpartum haemorrhage, whereas uterine relaxants are used, much less effectively, to delay labour. There is a section on drugs for erectile dysfunction, which have made a remarkable transition from below-the-counter charlatanry to medical orthodoxy.

Because of their ease of use and efficacy, oral contraceptive pills are the most widely used form of hormonal contraception. They act by suppressing ovulation, changing cervical mucus, and altering the endometrium. The current formulations are made from synthetic estrogens and progestins. The estrogen component of the pill consists of ethinyl estradiol or mestranol, which is metabolized to ethinyl estradiol. Multiple synthetic progestins are used. Norethindrone and its derivatives are used in many formulations [1]. 
Low-dose norgestimate and the more recently developed progestins (desogestrel, gestodene, and drospirenone) have a less androgenic profile; Levonorgestrel appears to be the most androgenic of the progestins and should be avoided in patients with hyperandrogenic symptoms. The three major formulations of oral contraceptives are (1) fixed-dose estrogen-progestin combination, (2) phasic estrogen-progestin combination, and (3) progestin only.

Each of these formulations is administered daily for 3 weeks followed by a week of no medication during which menstrual bleeding generally occurs. Two extended oral contraceptives have recently been approved for use in the United States; Seasonalle is a three month preparation with 84 days of active drug and 7 day of placebo, Lybrel is a continuous preparation containing $90 \mathrm{~g}$ of levonorgestrel and $20 \mathrm{~g}$ of ethinyl estradiol. Current doses of ethinyl estradiol range from $20-50 \mathrm{~g}$. However, indications for the 50-g dose are rare, and the majority of formulations contain $35 \mathrm{~g}$ of ethinyl estradiol [2].

The reduced estrogen and progesterone content in the second- and third-generation pills has decreased both side effects and risks associated with oral contraceptive use. At the currently used doses, patients must be cautioned not to miss pills due to the potential for ovulation. Side effects, including break-through bleeding, amenorrhea, breast tenderness, and weight gain, are often responsive to a change in formulation.

The microdose progestin-only minipill is less effective as a contraceptive, having a pregnancy rate of 2-7 per 100 women-years. However, it may be appropriate for women with cardiovascular disease or for women who cannot tolerate synthetic estrogens [3].

Progesterone is the most important progestin in humans. In addition to having important hormonal effects, it serves as a precursor to the estrogens, androgens, and adrenocortical steroids. It is synthesized in the ovary, testis, and adrenal from circulating cholesterol. Large amounts are also synthesized and released by the placenta during pregnancy.

Synthetic Progestins A variety of progestational compounds have been synthesized. Some are active when given by mouth. They are not a uniform group of compounds, and all of them differ from progesterone in one or more respects. In general, the 21-Carbon compounds (Hydroxyprogesterone, Medroxyprogesterone, Megestrol, and Dimethisterone) are the most closely related, pharmacologically as well as chemically, to progesterone. A new group of third-generation synthetic progestins has been introduced, principally as components of oral contraceptives. These neither "19-nor, 13ethyl" steroid compounds include desogestrel, gestodene, and norgestimate. They are claimed to have lower androgenic activity than older synthetic progestins [2].

Drosophila was chosen for our research work since it is the cornerstone experimental animal in the study of cellular and molecular genetics for over 50 years has been the ubiquitous fruit fly (Drosophila melanogaster). Whether mutated to a wingless, white-eyed, or barred, phenotype, or wild, it is the fruit fly that each budding geneticist is first exposed to. More recently, Drosophila are playing a starring role in developmental biology with particular emphasis on this dipteran's embryonic stages. Because they are easy to feed, breed, and maintain in a laboratory setting and their twoweek life cycle is relatively short, fruit flies will certainly continue to shine as experimental specimens. This includes the newer fields of gene therapy and genetic engineering as the map of the Drosophila genome is completed. Part of the reason people work on it is historical - so much is already known about it that it is easy to handle and well-understood and part of it is practical: it's a small animal, with a short life cycle of just two weeks, and is cheap and easy to keep large numbers. Mutant flies, with defects in any of several thousand genes are available, and the entire genome has recently been sequenced [14].

\section{Materials and methods}

\subsection{Preparation of wheat cream media (WC media)}

The media bottles was washed in tap water and then processed with distilled water and were further sterilized in hot air oven at $60^{\circ} \mathrm{C}$ for 5-6 hrs. Distilled water $(100 \mathrm{~mL})$ is added into $250 \mathrm{~mL}$ beaker. Jaggery $(10 \mathrm{~g})$ was added to the boiling water and it was smashed while dissolving, Broken Wheat $(10 \mathrm{~g})$ was added with continuous stirring. Agar agar (0.8g) is supplemented slowly with incessant stirring. Propionic acid $(1.5 \mathrm{~mL})$ was added as it acts as an antibacterial and antifungal agent. The viscosity of the media is checked before pouring into the media bottles.

\subsection{Preparation of LNGL medicated Wheat cream media (WC media)}

The media bottles was washed in tap water and then processed with distilled water and were further sterilized in hot air oven at $60^{\circ} \mathrm{C}$ for $5-6 \mathrm{hrs}$. Distilled water $(100 \mathrm{~mL})$ is added into $250 \mathrm{~mL}$ beaker. Jaggery $(10 \mathrm{~g})$ was added to the boiling water and it was smashed while dissolving, Broken Wheat $(10 \mathrm{~g})$ was added with continuous stirring. Agar agar (0.8g) is supplemented slowly with incessant stirring. Propionic acid $(1.5 \mathrm{~mL})$ was added as it acts as an antibacterial and antifungal agent. Finely homogenized pure form of Levonorgestrel (LNGL) drug is added to the media at $80^{\circ} \mathrm{C}$ at 
different dosages from $0.1 \mathrm{mg}$ to $2 \mathrm{mg}$ and $3 \mathrm{mg}$ respectively. The viscosity of the media is checked before pouring into the media bottles.

\subsection{Inoculation of $q \&$ Drosophila melanogaster}

Oregon wild type flies were selected for our research work. The male and female flies were anesthetized using Ether. A pair of anesthetized flies is transferred into the medicated media bottles. The bottles are plugged with sterilized cotton plugs. The first generation and second generation specimens were used for biochemical analysis.

\subsection{Characterization of Levonorgestrel molecule by Mass Spectroscopy and Infrared Radiation}

Levonorgestrel sample was submitted to NewChem Technologies, School of Medicinal Chemistry, Newcastle University, United Kingdom. $1 \mathrm{mg} / \mathrm{mL}$ of LNGL was submitted for LC-MS with the molecular formula $\mathrm{C}_{21} \mathrm{H}_{28} \mathrm{O}_{2}$ and exact isotopic mass of 312.2089. The sample was soluble in Dimethylsulfoxide as a solvent.

Sample was submitted to Infrared radiation at Analytical Laboratory, School of Medicinal Chemistry. 0.5 mg of LNGL was crushed and an IR spectrum was recorded as Levonorgestrel-LNGL [9].

\subsection{Isolation of Proteins from Drosophila melanogaster by Camiolo buffer method}

To isolate the proteins from Drosophila melanogaster treated with medicated LNGL media with drug dosage from $0.1 \mathrm{mg}$ to $3.0 \mathrm{mg}$

The wet weight $0.1 \mathrm{~g}$ of Drosophila melanogaster / 3rd instar Larva is weighed, subject the experimental specimen in aluminum foil and crush the specimen and freeze the tissue in liquid Nitrogen, rinse in 1M PBS solution and mince, then add freshly prepared $1 \mathrm{~mL}$ of Camiolo extraction buffer per $0.1 \mathrm{~g}$ of tissue and homogenize for $1 \mathrm{~min}$ at $4^{\circ} \mathrm{C}$, centrifuge the sample at $3000 \mathrm{rpm}$ for $15 \mathrm{~min}$ at $4^{\circ} \mathrm{C}$. The supernatant and pellet is removed and saved in another tube [4].

\subsection{Estimation of Proteins from Drosophila melanogaster by Lowry's method}

The blue color developed by the reduction of the phosphomolybdate and phosphotungstic components in the Folin Ciocalteau reagent by the amino acid tyrosine and tryptophan present in the protein plus the color developed by biuret reaction of the protein with the alkaline cupric tartrate is measured in the Lowry's method. The absorbance was recorded at 660 O.D [4].

\subsection{Separation of Proteins by SDS- PAGE}

The analytical electrophoresis of proteins is carried out in polyacrylamide gels under conditions that ensure dissociation of the proteins into their individual polypeptide subunits and that minimize aggregation. Most commonly the strongly anionic detergent Sodium Dodecyl Sulphate (SDS) is used in combination with a reducing agent and heat to dissociate the proteins before they are loaded on the gel. The denatured polypeptides bind SDS and become negatively charged. Because the amount of SDS bound is always is almost always proportional to the molecular weight of the polypeptide and is independent of its sequence, SDS-polypeptide complexes migrate through polyacrylamide gels in accordance with the size of polypeptide. At saturation, approximately $1.4 \mathrm{~g}$ of detergent is bound per gram of polypeptide. By using markers of known molecular weight of the polypeptide chains [5].

\subsection{Isolation of Lipids from Drosophila melanogaster by Bloor's mixture}

Isolation of total lipid content from Drosophila melanogaster cultured in medicated Levonorgestrel media from $0.1 \mathrm{mg}$ to $3.0 \mathrm{mg}$ LNGL.

A mixture of Ethyl ether and Ethanol in the ratio of 3:1 is used. The tissue, about $1 \mathrm{~g}$ wet weight, is homogenized well in a mortar and pestle with about $10 \mathrm{~mL}$ of the solvent mixture. If the tissue is tough, a small amount of acid washed sand can be added during homogenizing. After homogenization, the extract is centrifuged at $2000 \mathrm{rpm}$ for $10 \mathrm{~min}$, and the clear extract is taken in a separation funnel. To this $2 \mathrm{~mL}$ of $0.05 \mathrm{M} \mathrm{KCl}$ solution is added and shaken well. Two layers will separate and forms a bilayer. While the water in $\mathrm{KCl}$ solution helps in layer separation, the salt prevents any emulsification [7]. 


\subsection{Estimation and quantification of Lipids from Drosophila melanogaster}

The lipid sample $(1 \mathrm{~mL})$ was added into chloroform and $500 \mu \mathrm{L}$ of copper reagent was added and was mixed using cyclomixer for $2 \mathrm{~min}$. The mixture was centrifuged at $2000 \mathrm{rpm}$ for $10 \mathrm{~min}$ at $4^{\circ} \mathrm{C}$. The upper aqueous layer was aspirated and discarded. To the organic chloroform layer $150 \mu \mathrm{L}$ of $1 \%$ of $0.1 \%$ sodium diethyl-dithiocarbonate solution was added and mixed. The absorbance was read at $440 \mathrm{~nm}$ [7].

\subsection{Isolation of Carbohydrates from Drosophila melanogaster}

Tissues are extracted in different solvents for different lengths of time. Some of the solvents are capable of penetrating the tissues rapidly and stop enzymatic activity. Plant constituent possess different degrees of solubility in different solvents. Water is the best solvent for almost all the substances present in the tissues but does not penetrate tissues quick enough to stop enzymatic activity. Alcohol is highly effective in penetrating tissues and stopping the enzymatic activity. Boiling alcohol is more effective than cold alcohol. Hence, it is advisable that tissue for analysis be extracted in boiling $80 \%$ alcohol.

Grind a known weight of material in boiling $80 \%$ ethyl alcohol $(5-10 \mathrm{~mL} / \mathrm{g}$ material) thoroughly in a mortar with pestle or in a blender for 5-10 min and cool under cold water. Pass the extract through two layers of cheese cloth.

Pool both the extracts together and filter through Whatman No. 41 filter paper. Collect the filtrate, note the volume and store in sealed vials at $0-4^{\circ} \mathrm{C}$ until use. The residue can be dried, weighed and preserved in air tight containers at $0-4{ }^{\circ} \mathrm{C}$. The preserved alcohol extract and residue can be used for analysis of various compounds [7].

\subsection{Isolation of Carbohydrates from Drosophila melanogaster by Anthrone method}

The anthrone reaction is the basic of a rapid and convenient method for the determination of hexoses, aldopentoses and hexuronoc acids either free of present in polysaccharides. Carbohydrates are dehydrated by concentrated Sulphuric acid to form furfural. Furfural condenses with anthrone (10-keto-9, 10-dihydroanthracene) to form a blue - green complex which is measured colorimetrically at $630 \mathrm{~nm}$.

Weigh $1 \mathrm{~g}$ of the sample into a boiling tube. Hydrolyze by keeping it in a boiling water bath for 3 hours with $5 \mathrm{~mL}$ of $2.5 \mathrm{~N} \mathrm{HCl}$ and cool at room temperature. Neutralize it with solid sodium carbonate until the effervescence ceases. Make up the volume to $100 \mathrm{~mL}$ and centrifuge. Collect the supernatant and take 0.5 and $1 \mathrm{~mL}$ aliquots for analysis. Prepare the standards by taking $0.0,0.2,0.4,0.6,0.8$, and $1 \mathrm{~mL}$ of the working standard. ' 0 ' serves as blank. Make up the volume to $1 \mathrm{~mL}$ in all the tubes including the sample tubes by adding distilled water. Then add $4 \mathrm{~mL}$ of anthrone reagent. The tubes were heated for $8 \mathrm{~min}$ in boiling water bath. Cool rapidly and read the green to dark green color at $630 \mathrm{~nm}$.

From the graph calculate the amount of carbohydrates present in the sample [7].

Amount of Carbohydrate: Sugar value from graph $(\mathrm{mg}) X$ Total volume of extract $(\mathrm{mL}) \mathbf{X} 100$ Aliquot sample used (0.5 or $1 \mathrm{ml})$ Wt. of Sample

\subsection{Detection of $\beta$-Galactosidase activity in Drosophila melanogaster with LNGL dosage}

When $\beta$-Gal cleaves the glycosidic linkage in X-Gal, a soluble, colorless indoxyl monomer is produced. Subsequently, two of the liberated indoxyl moieties form a dimer which is non-enzymatically oxidized. The resultant halogenated indigo is a very stable and insoluble blue compound. The dimerization and oxidation reactions require transfer of an electron, which is facilitated by electron acceptors of the proper redox potential. The ferric and ferrous ions included in most X-gal reaction buffers provide this function. Tetrazolium salts, which can serve as the final electron acceptors, also can be added, and precipitate when reduced to form colored formazan compounds. Phenazine methosulfate (PMS) can further increase this reaction rate by quantitatively reducing tetrazolium salts.

Dechorionate was added to the embryos with $50 \%$ Bleach and the embryos were rinsed well with DM- $\mathrm{H}_{2} \mathrm{O}$ and collect them on a Nitex Mesh. Blot the mesh on tissue paper to remove the excess water. In a deep depression slide, fix embryos in $0.5 \mathrm{~mL}$ of Heptane that is saturated with the Fixative for $15 \mathrm{~min}$ at room temperature. Cover the wells with a glass slide to prevent the Heptane from evaporating. Transfer the embryos onto a glass slide using a Pasteur pipette. Using a piece of filter paper, remove the excess heptane. After all the Heptane has evaporated, take the embryos by gently touching them using double-sticky sided tape and stick the tape on a glass slide, embryo side up.

Cover the embryos with a drop of PBS. Devitellinize the embryos using a dissection needle (a tungsten needle is not necessary. Transfer the embryos to a microcentrifuge tube. Remove the PBS and add about $300 \mu \mathrm{L}$ of Staining Solution without X-Gal (i.e. Fe/Phosphate or Fe/CP). Incubate at room temperature for about $5 \mathrm{~min}$. Remove the liquid and replace it with Staining Solution. Incubate from $2 \mathrm{hr}$ to overnight at room temperature or $37^{\circ} \mathrm{C}$. Remove the Staining Solution. Rinse the embryos by vortexing once in $70 \%$ Ethanol and once in $100 \%$ Ethanol. Store the embryos in $90 \%$ Glycerol/PBS at $4{ }^{\circ} \mathrm{C}$. They can be kept for months at this stage. Mount using coverslips as spacers [13], [15], [16]. 


\section{Results}

\subsection{Analytical evidence for LNGL by LCMS and IR spectroscopy}

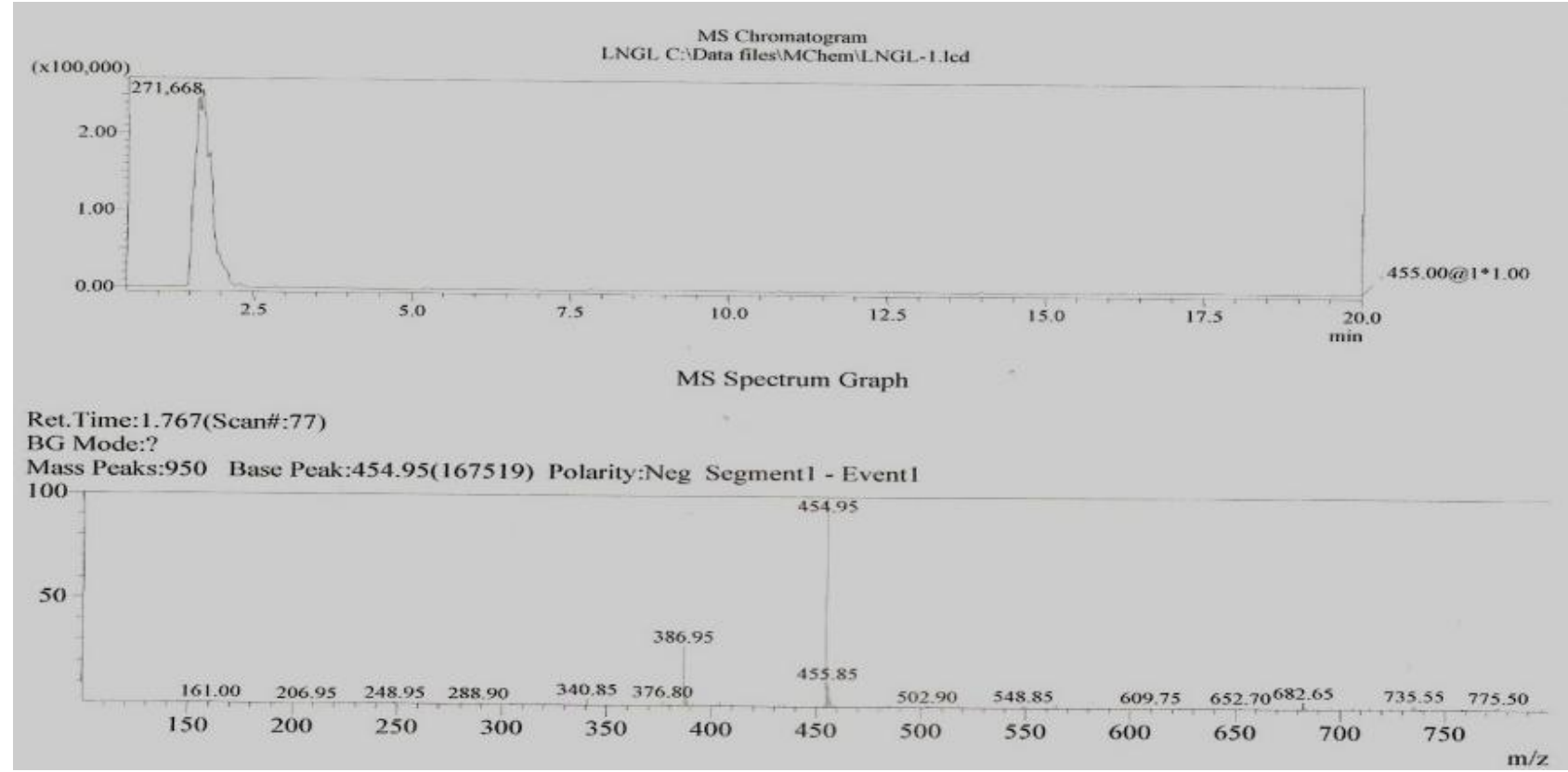

Fig. 1: LC-MS Spectra of Levonorgestrel with ribose sugar coat $(\mathrm{M}+\mathrm{Z})=454.95$

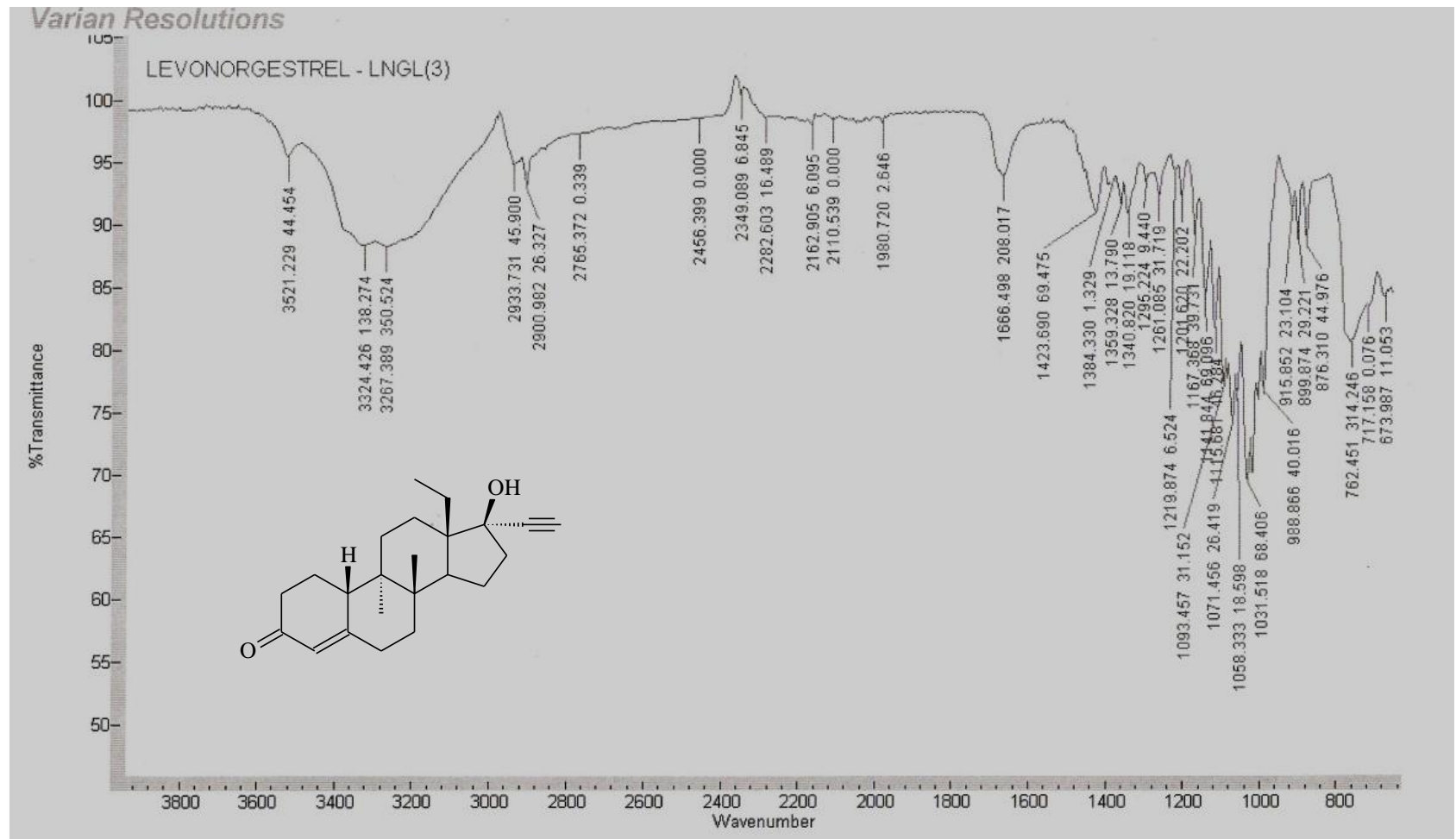

Fig. 2: IR Spectra of Levonorgestrel-LNGL(3); C-C stretch 1423.694, C=O stretch 1666.498, C-H (Ar) stretch 2900.982-2933.731, O-H stretch 3521.229 
3.2 Illustration of growth rate of Drosophila melanogaster administered with different drug dosage of LNGL

Table 1: Study of Life cycle in Drosophila melanogaster treated with LNGL (0.1 $\mathrm{mg}$ to $0.8 \mathrm{mg}$ )

\begin{tabular}{cccccccccc}
\hline Parameters & Control & $\begin{array}{c}0.1 \mathrm{mg} \\
\text { LNGL }\end{array}$ & $\begin{array}{c}0.2 \mathrm{mg} \\
\text { LNGL }\end{array}$ & $\begin{array}{c}0.3 \mathrm{mg} \\
\text { LNGL }\end{array}$ & $\begin{array}{c}0.4 \mathrm{mg} \\
\text { LNGL }\end{array}$ & $\begin{array}{c}0.5 \mathrm{mg} \\
\text { LNGL }\end{array}$ & $\begin{array}{c}0.6 \mathrm{mg} \\
\text { LNGL }\end{array}$ & $\begin{array}{c}0.7 \mathrm{mg} \\
\text { LNGL }\end{array}$ & $\begin{array}{c}0.8 \mathrm{mg} \\
\text { LNGL }\end{array}$ \\
\hline o fly & 1 & 3 & 1 & 1 & 1 & 1 & 1 & 1 & 1 \\
+ fly & 1 & 6 & 1 & 1 & 9 & 1 & 1 & 1 & 7 \\
Eggs (Bunches) & 1 & 6 & 2 & 2 & 6 & 2 & 4 & 2 & 4 \\
Embryos & 6 & 11 & 25 & 60 & 150 & 85 & 65 & 30 & 120 \\
$1^{\text {st }}$ instar Larvae & 2 & 10 & 0 & 15 & 10 & 5 & 0 & 2 & 5 \\
$2^{\text {nd }}$ instar Larvae & 8 & 32 & 1 & 4 & 4 & 9 & 1 & 4 & 8 \\
$3^{\text {rd instar Larvae }}$ & 7 & 11 & 1 & 3 & 0 & 7 & 2 & 5 & 1 \\
Pre - Pupa & 0 & 15 & 1 & 0 & 13 & 1 & 1 & 0 & 9 \\
Pupa & 4 & 2 & 0 & 0 & 4 & 0 & 0 & 0 & 7 \\
\hline
\end{tabular}

Table 2: Study of Life cycle in Drosophila melanogaster treated with LNGL (0.9mg to $1.7 \mathrm{mg})$

\begin{tabular}{|c|c|c|c|c|c|c|c|c|c|}
\hline Parameters & $\begin{array}{l}0.9 \mathrm{mg} \\
\mathrm{LNGL}\end{array}$ & $\begin{array}{l}1 \mathrm{mg} \\
\mathrm{LNGL}\end{array}$ & $\begin{array}{l}1.1 \mathrm{mg} \\
\mathrm{LNGL}\end{array}$ & $\begin{array}{l}1.2 \mathrm{mg} \\
\mathrm{LNGL}\end{array}$ & $\begin{array}{l}1.3 \mathrm{mg} \\
\mathrm{LNGL}\end{array}$ & $\begin{array}{l}1.4 \mathrm{mg} \\
\mathrm{LNGL}\end{array}$ & $\begin{array}{l}1.5 \mathrm{mg} \\
\mathrm{LNGL}\end{array}$ & $\begin{array}{l}1.6 \mathrm{mg} \\
\mathrm{LNGL}\end{array}$ & $\begin{array}{l}1.7 \mathrm{mg} \\
\mathrm{LNGL}\end{array}$ \\
\hline$\sigma^{\lambda}$ fly & 1 & 2 & 1 & 1 & 1 & 1 & 1 & 1 & 1 \\
\hline q fly & 7 & 5 & 4 & 3 & 6 & 7 & 1 & 1 & 1 \\
\hline Eggs (Bunches) & 3 & 5 & 4 & 3 & 4 & 6 & 5 & 4 & 3 \\
\hline Embryos & 25 & 40 & 20 & 50 & 98 & 108 & 50 & 30 & 38 \\
\hline $1^{\text {st }}$ instar Larvae & 6 & 4 & 2 & 6 & 9 & 13 & 5 & 10 & 2 \\
\hline $2^{\text {nd }}$ instar Larvae & 15 & 6 & 0 & 0 & 6 & 9 & 2 & 17 & 0 \\
\hline $3^{\text {rd }}$ instar Larvae & 7 & 0 & 0 & 0 & 4 & 7 & 0 & 8 & 0 \\
\hline Pre - Pupa & 0 & 0 & 0 & 0 & 5 & 8 & 0 & 11 & 0 \\
\hline Pupa & 0 & 1 & 0 & 0 & 5 & 5 & 0 & 0 & 0 \\
\hline
\end{tabular}

Table 3: Study of Life cycle in Drosophila melanogaster treated with LNGL (1.8mg to 3.0mg)

\begin{tabular}{|c|c|c|c|c|c|}
\hline Parameters & $\begin{array}{l}1.8 \mathrm{mg} \\
\mathrm{LNGL}\end{array}$ & $\begin{array}{l}1.9 \mathrm{mg} \\
\mathrm{LNGL}\end{array}$ & $\begin{array}{l}2.0 \mathrm{mg} \\
\mathrm{LNGL}\end{array}$ & $\begin{array}{l}2.5 \mathrm{mg} \\
\mathrm{LNGL}\end{array}$ & $\begin{array}{l}3.0 \mathrm{mg} \\
\mathrm{LNGL}\end{array}$ \\
\hline ঠे fly & 1 & 1 & 1 & 1 & 1 \\
\hline$q$ fly & 1 & 1 & 1 & 1 & 1 \\
\hline Eggs (Bunches) & 2 & 3 & 4 & 2 & 3 \\
\hline Embryos & 40 & 340 & 380 & 400 & 360 \\
\hline $1^{\text {st }}$ instar Larvae & 1 & 4 & 6 & 7 & 5 \\
\hline $2^{\text {nd }}$ instar Larvae & 0 & 6 & 3 & 3 & 4 \\
\hline $3^{\text {rd }}$ instar Larvae & 0 & 0 & 0 & 6 & 5 \\
\hline Pre - Pupa & 0 & 0 & 0 & 32 & 40 \\
\hline Pupa & 0 & 0 & 0 & 0 & 0 \\
\hline
\end{tabular}

\subsection{Effect of LNGL on Proteomic profile}

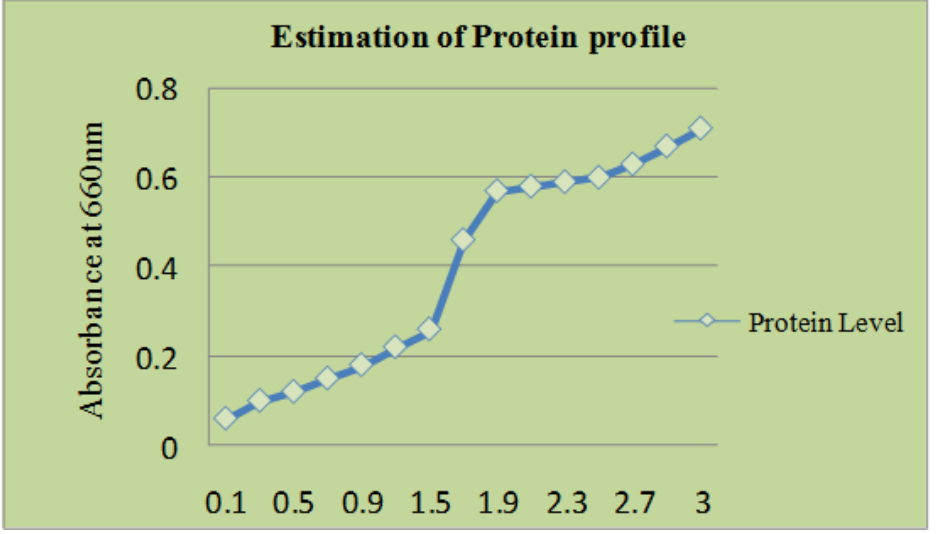

Fig. 3: Estimation of protein by Lowry's method 

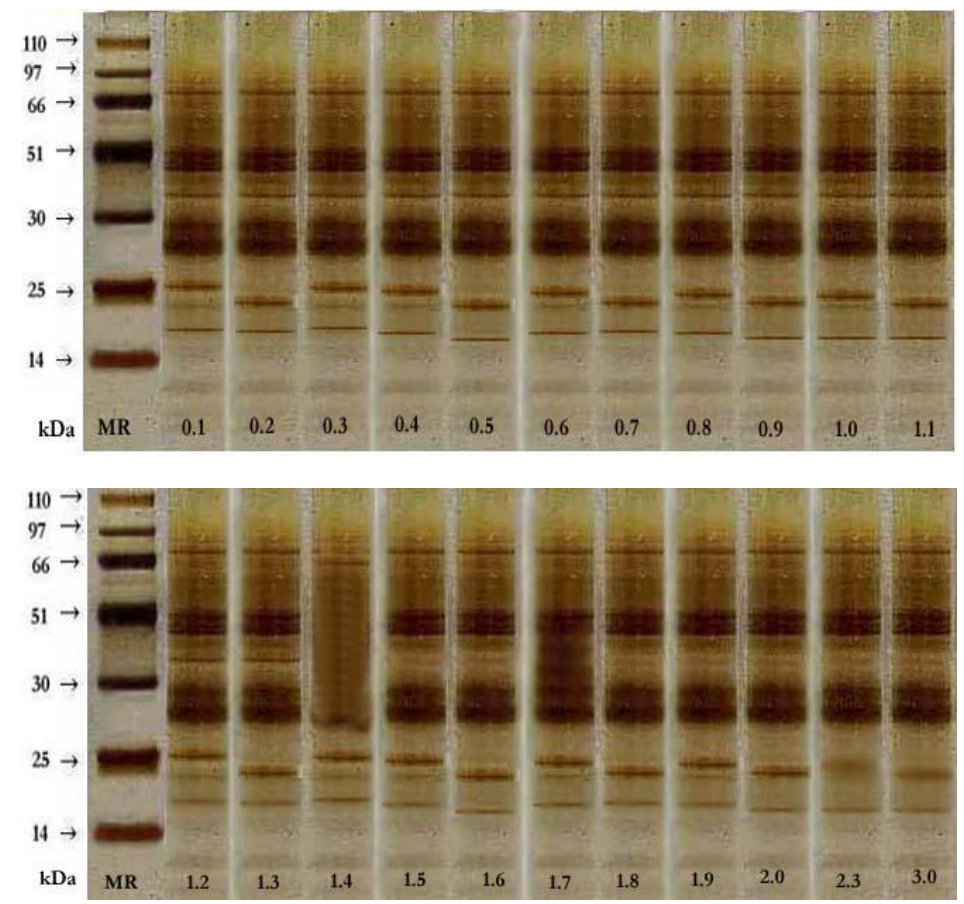

Fig. 4: Separation of proteins from $0.1 \mathrm{mg}$ to $3 \mathrm{mg}$ LNGL by SDS-PAGE

\subsection{Effect of LNGL on Glycomic profile}

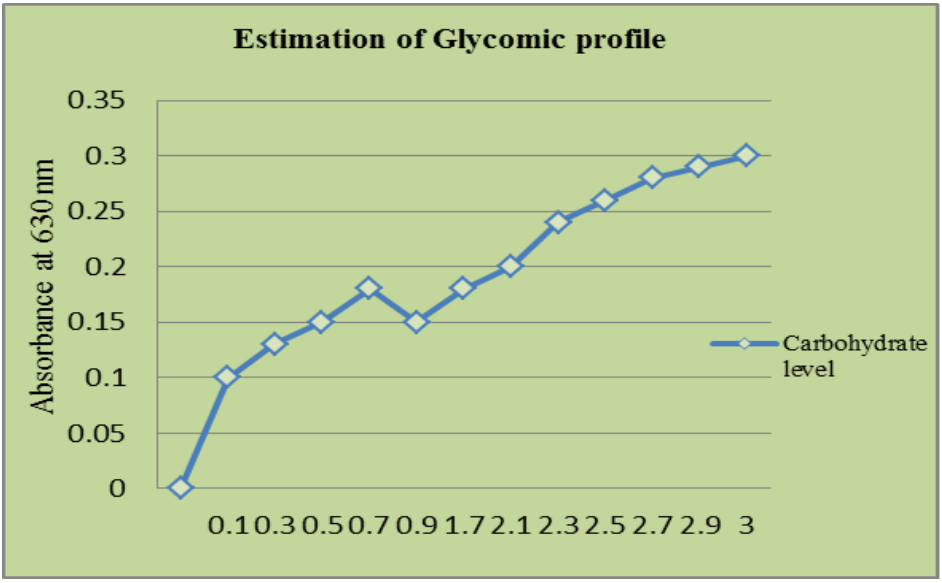

Fig. 5: Estimation of carbohydrates by anthrone method

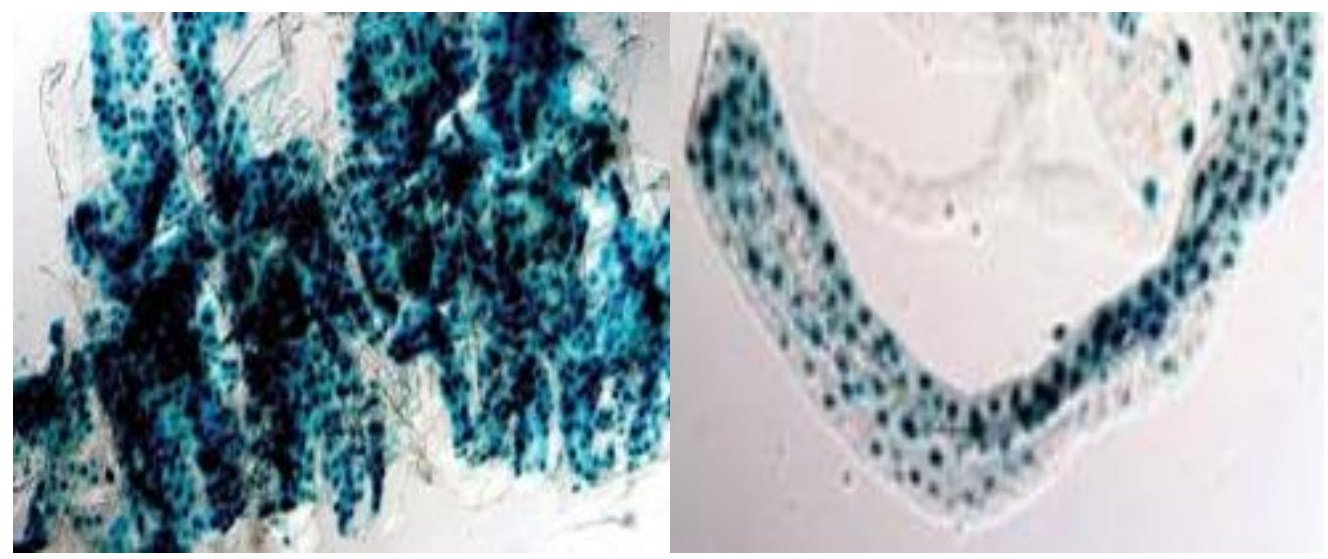

Carcass

Hind gut

Fig. 6:Staining with X-gal detects the $\beta$-galactosidase activity in Drosophila melanogaster 


\subsection{Effect of LNGL on Lipidomic profile}

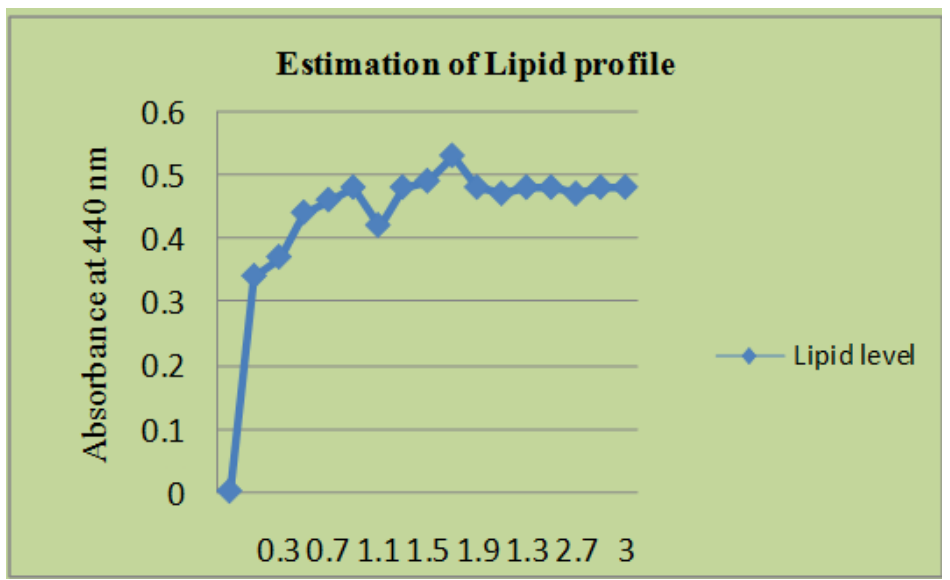

Fig. 7: Estimation and quantification of lipids

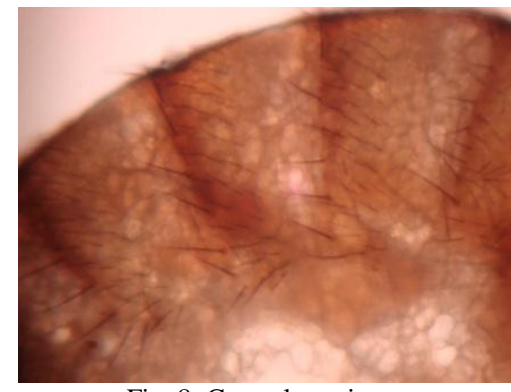

Fig. 8: Control specimen

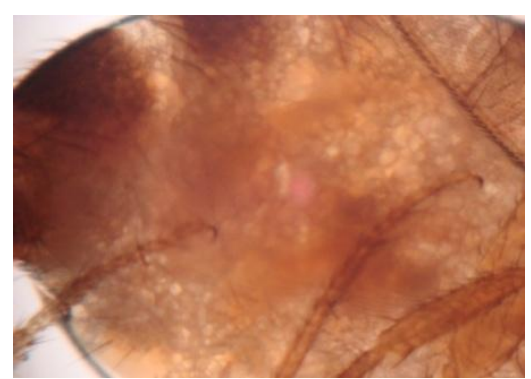

Fig. 10: Specimen treated with $2.0 \mathrm{mg}$ LNGL deposition of lipid in abdomen

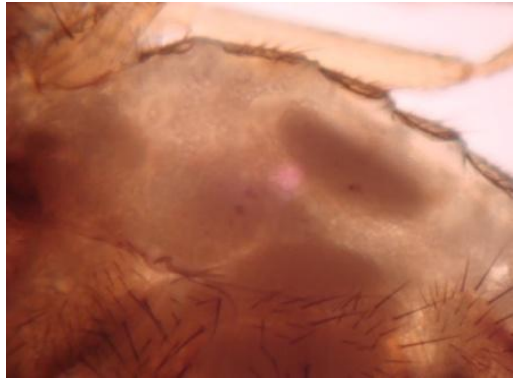

Fig. 9: Specimen treated with 1.0 mg LNGL deposition of lipid in abdomen

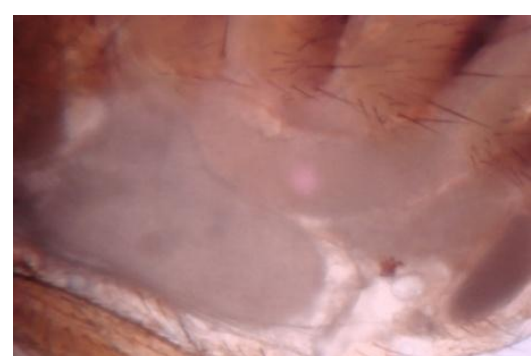

Fig. 11: Specimen treated with $2.5 \mathrm{mg}$ LNGL deposition of lipid in abdomen

Fig. 12: Specimen treated with $3.0 \mathrm{mg}$ LNGL shows deposition of lipid and depletion of bands in abdomen 
Table 4: Survey on consumption of Levonorgestrel oral contraceptive pills in Bangalore, India

\begin{tabular}{|c|c|c|c|c|}
\hline Parameters & A & $\mathrm{B}$ & $\mathrm{C}$ & $\mathrm{D}$ \\
\hline Age & 27 & 32 & 25 & 28 \\
\hline Occupation & Engineer & Doctor & Scientist & Housewife \\
\hline Blood group & $\mathrm{A}^{+\mathrm{ve}}$ & $\mathrm{A}^{+\mathrm{ve}}$ & $\mathrm{O}^{+\mathrm{ve}}$ & $\mathrm{B}^{-\mathrm{ve}}$ \\
\hline Blood Pressure & 100/70 mm Hg & $120 / 80 \mathrm{~mm} \mathrm{Hg}$ & $110 / 90 \mathrm{~mm} \mathrm{Hg}$ & $120 / 90 \mathrm{~mm} \mathrm{Hg}$ \\
\hline Pulse rate & 72 beats/min & 70 beats/min & 76 beats/min & 72 beats/min \\
\hline Blood sugar & $110 \mathrm{~mm}$ & $110 \mathrm{~mm}$ & $120 \mathrm{~mm}$ & $108 \mathrm{~mm}$ \\
\hline $\begin{array}{l}\text { Are you regularly } \\
\text { using chill pill }\end{array}$ & Yes & Yes & Yes & Yes \\
\hline $\begin{array}{l}\text { Body weight before } \\
\text { using the pill }\end{array}$ & 65 & 55 & 51 & 53 \\
\hline $\begin{array}{l}\text { Body weight after } \\
\text { using the pill }\end{array}$ & 68 & 63 & 58 & 61 \\
\hline Any other symptoms & NA & NA & NA & NA \\
\hline
\end{tabular}

\section{Discussion}

Our research was focused on Levonorgestrel drug due to the large intake of oral contraceptive pills by the teenage group. Youngsters are not aware of the toxicological effects of LNGL on the biochemical pathway, our research team focused to delve the toxicity of over dosage of LNGL hampering biochemical pathways such as protein, carbohydrate and the lipid metabolism. We administered our drug molecule of interest into Drosophila melanogaster with different drug dosage from $0.1 \mathrm{mg}$ upto the level of $3 \mathrm{mg}$.

Drastic variation in metabolism was observed in the specimen treated with LNGL drug dosage level with respect to control specimen.

Protein metabolism was our target study, protein profile in the specimen increases with respect to increase in the drug dosage of LNGL in the nutrition media. SDS-PAGE (Fig.4) shows the depletion of bands with the specimen administered with 2.5 and $3.0 \mathrm{mg}$ of LNGL at the molecular weight of $25 \mathrm{kDa}$. This shows the variation in the amino acids.

Glycomic study involves nuclear receptor 4A DHR 38 in Drosophila melanogaster which controls and maintains the proper uptake and storage of glycogen during the growing larval stage of development. Specimens administered with drug dosage of LNGL shows the large level of glycomic content there by nullifying DHR 38 and inhibiting phosphoglucomutase enzyme and reduction of amylase enzyme activity [13]. X-Gal staining (Fig.6) processed for carcass and hindgut of specimen administered with LNGL shows the accumulation of glycogen in the specimen.

The nuclear receptor PPAR gamma plays a vital role in lipid metabolism. The PPAR gamma binds to the oxidized fatty acids that likely to be the natural ligands to these receptors. There by the oxidation of fatty acids brings about the activation of PPAR gamma. In the specimens treated with LNGL shows the deposition of lipids in the abdomen and depletion of the abdominal bands. The deposited fatty acids don't get oxidized and thereby inactivates the PPAR gamma. The morphological study of the specimen shows the huge deposition of triglycerides. As the dosage of LNGL increases, the specimen takes more deposition of fatty acids and depletion of abdominal band. (Fig.9 -12) [17].

\section{Summary}

The study of biochemical analysis revealed the toxicity of Levonorgestrel takes place when administered regularly with over dosage. The study of Proteomics, Glycomics, Lipids and Morphological studies reveals the adverse effects on the normal metabolic pathways. The Mass Spectroscopy and Infrared Radiation confirms to the proposed structure. The protein and glycomic profile drastically increases as the dosage of LNGL increases. The specimen shows the accumulation of triglycerides in the abdominal region and depletion of abdominal bands. We can finally summarise with the conception of patient survey that administration of over-dosage of LNGL in regular intervals in specimens alters the metabolic pathway. 


\section{Acknowledgements}

Authors are extremely gratified and obliged to Mr. Jestin V Thomas, Managing Director of Leads Clinical Research and Bioservices Pvt Ltd for their encouragement and in inculcating research culture in every one of us.

Authours profusely acknowledge Mrs. Anitha Kasa (LCMS Analyst), Dr. Pedro R Villuendas, Dr. Carl Young NewChem Technologies, School of Medicinal Chemistry, Newcastle University, United Kingdom.

We would like to thank Dr. Jyothi Assistant Professor, Department of Medical Pharmacology and Dr. Pushpalatha Assistant Professor, Department of Anatomy in Kempegowda Institute of Medical Sciences (KIMS) Bangalore, for supporting me, helping and providing me the subjects related to my Survey from various Gynecology department in different hospitals in and around Bangalore and in completing this report.

\section{References}

[1] Fauci, Braunwald, Kasper, Hauser,Longo, Jameson, Loscalzo, Harrison's Principles of Internal Medicine 17th edition, 2012, Boston.

[2] H.P Rang, M.M Dale, J.M Ritter, R.J. Flower, Rang and Dales Pharmacology 6th edition 2012, England.

[3] Bertram G. Katzung, Basic and Clinical Pharmacology 11th edition,2009, San Francisco.

[4] J. Jayaraman, Laboratory manual in Biochemistry, Madurai Kamaraj University, 10th edition, 2008, India.

[5] S. Sadasivam and A. Manickam, Biochemical methods, 3rd edition, 2007, India.

[6] Ginsburg, M., Snow, M. H. L. \& McLaren, A. 5th edition, 1990, Cambridge, U.K.

[7] S.K Thimmaiah, Standard methods of Biochemical Analysis, University of Agricultural Sciences GKVK Campus, 4th edition, 2009, Bangalore, India.

[8] George Rouser, A.J Bauman, Gene Kritchevsky, New methods for the separation and quantitative isolation of Lipids, The American Journal of Chemical Nutrition, Vol 9, 1961.

[9] Sandor Gorog, The sacred cow: the questionable role of assay methods in characterizing the quality of bulk Pharmaceuticals Journal of Pharmaceutical and Biomedical Analysis 36 (2005) 931-937.

[10] Erin Gainer, Christian Mery, Andre Ulmann, Levonorgestrel-only emergency contraception: real-world tolerance and efficacy, Contraception 64 (2001) 17-21.

[11] David F. Archer, MD, Eberhard F. Mammen, MD, and Gary S. Grubb, MD, MPH, The effects of a low-dose monophasic preparation of levonorgestrel and ethinyl estradiol on coagulation and other hemostatic factors, Norfolk, Virginia, Detroit, Michigan, and Radnor, Pennsylvania, Am J Obstet Gynecol, Volume 181,Number 5, Part 2, 1999.

[12] Marie R. Rodway, Cynthia L. Swan, Natasha K. Crellin, Carolina Gillio-Meina, P. Jorge Chedrese, Steroid regulation of progesterone synthesis in a stable porcine granulosa cell line: a role for progestins, Journal of Steroid Biochemistry and Molecular Biology Vol 68, 173$180,1999$.

[13] Anne-Franc, oise Ruaud, Geanette Lam, and Carl S. Thummel, The Drosophila NR4A Nuclear Receptor DHR38 Regulates Carbohydrate Metabolism and Glycogen Storage, Mol Endocrinol, January 2011, 25(1)83-91

[14] J. Aaron Cassill, Michael Whitney, Claudio A. P. Joazerio, Ann Becker and Charles S. Zuker, Isolation of drosophila genes encoding G protein-coupled receptor kinases, Proc. Nati. Acad. Sci. USA Vol. 88, pp.11067-11070, 1991.

[15] Fire, A. Histochemical techniques for locating E. coli ß-galactosidase activity in transgenic organisms. Genet.Anal. Tech. Appl. 9:151, 1992.

[16] Miller, J. Experiments in Molecular Genetics, p. 352-355, 1972. Cold Spring Harbor Laboratory, NY

[17] Itoh T, Fairall L, Amin K, Inaba Y, Szanto A, Balint BL, Nagy L, Yamamoto K, Schwabe JWR. Structural. Basis for the activation of PPAR gamma by oxidised fattyacids. Nat Struct Mol Biol 2008, 15: p. 924-931. 